\title{
Experimental study of geotextile as plinth beam in a pile group-supported modeled building frame
}

\author{
C. Ravi Kumar Reddy ${ }^{1}$ T. D. Gunneswara $\operatorname{Rao}^{2}$
}

Received: 21 October 2016/Accepted: 13 September 2017/Published online: 20 September 2017

(c) The Author(s) 2017. This article is an open access publication

\begin{abstract}
This paper presents the experimental results of static vertical load tests on a model building frame with geotextile as plinth beam supported by pile groups embedded in cohesionless soil (sand). The experimental results have been compared with those obtained from the nonlinear FEA and conventional method of analysis. The results revealed that the conventional method of analysis gives a shear force of about $53 \%$, bending moment at the top of the column about $17 \%$ and at the base of the column about $50-98 \%$ higher than that by the nonlinear FEA for the frame with geotextile as plinth beam.
\end{abstract}

Keywords Soil structure interaction - Plinth beam ·

Geotextile · Pile group · Cohesionless soil · Building frame

\section{Introduction}

Soil settlement is a function of the flexural rigidity of the superstructure. The influence caused by the settlement of the supporting ground on the response of framed structures was often ignored in structural design. The structural stiffness can have a significant influence on the distribution of the column loads and moments transmitted to the foundation of the structure. Previous studies have, however, indicated that the effect of interaction between soil and structure can be quite significant. Interaction analyses

C. Ravi Kumar Reddy

ravibecnitw@gmail.com

1 Department of Civil Engineering, KHIT, Guntur, A. P 522019, India

2 Department of Civil Engineering, NIT, Warangal 506004, India have been reported in numerous previous studies such as Meyerhof (1947, 1953), Chamecki (1956), Morris (1966), Lee and Harrison (1970), Lee and Brown (1972), Subbarao et al. (and even a few studies in the recent past such as Deshmukh and Karmarkar (1991), Noorzaei et al. (Noorzaei et al. 1995), Srinivasa Rao et al. (1995), Dasgupta et al. (1998), Mandal et al. (1999), Basack (2008) and Basack and Purkayastha (2007). The common practice of obtaining foundation loads from the structural analysis without allowance for foundation settlement may, therefore, result in extra cost that might have been avoided had the effect of soil-structure interaction been taken into account in determining the settlements. This requires that the engineers not only understand the properties of the ground but they also need to know how the building responds to deformation and what the consequences of such deformation will be to the function of the building. In this regard, many analytical works have been reported on the building frames founded on pile groups by Buragohain et al. (1977), Ingle and Chore (2007) and Chore and Ingle (2008), Chore et al. and the experimental work by Reddy and Rao (2011). But no significant light was thrown on the direction of the effect of soil interaction on building frames with geotextile as plinth beam founded on pile groups.

The aim of this paper is to present an experimental investigation as well as numerical analysis through the nonlinear finite element analysis (FEA) of a model plane frame with geotextile as plinth beam supported by pile groups embedded in cohesionless soil (sand) under the static loads (central-concentrated load, uniformly distributed load (UDL) and eccentric-concentrated load). The need for consideration of soil interaction in the analysis of building frame with geotextile as plinth beam is emphasized by the experimental investigation by comparing the behavior of the frame obtained from the experimental and 
numerical analysis with that by the conventional method of analysis. An attempt is made to quantify the soil interaction effect on the response of the building frame in terms of displacements, rotations, shears and bending moments through the experimental investigation.

\section{Analytical programme}

\section{Analysis programme using ANSYS}

The analysis of the model plane frame with geotextile as plinth beam is carried out using ANSYS for the following cases:

1. Frame with fixed bases to evaluate the shear force and bending moment in the column, which is the usual practice done known as the conventional method.

2. Nonlinear analyses to evaluate the lateral displacements, vertical displacements and rotations, shear forces and bending moments on the frame.

3. Frame with bases released by imposing the lateral displacements, vertical displacements and rotations measured from the experiments for the corresponding loading on the frame to get the back-figured shear forces and bending moments generated in the columns.

\section{Nonlinear finite element analysis}

The nonlinear analyses were performed for the single-bay single-storeyed model plane frame with plinth beam founded on $2 \times 2$ pile groups in a sandy soil (Fig. 1). The columns, beams and piles are modeled using the 3D elastic two-noded BEAM elements. The pile cap is modeled using the fournoded elastic SHELL elements. The soil around the individual piles was modeled with nonlinear load transfer curves using the COMBIN39 elements. Geotextile which is used as plinth beam was also modeled using COMBIN39 elements.

The nonlinear constitutive soil models given by Eqs. (1)-(3) are employed for the present problem.

The lateral load transfer curves given by Eq. (1) were used as the API (1987) model,

$p=\bar{A}_{\mathrm{s}} P_{\mathrm{s}} \tanh \left(\frac{k Z}{\bar{A}_{\mathrm{s}} P_{\mathrm{u}}} y\right)$,

where $A_{\mathrm{s}}$ is the adjustment coefficient for the static $p-y$ curves, $P_{\mathrm{s}}$ governing ultimate soil resistance, $k$ initial subgrade reaction constant, $Z$ depth, and $P_{\mathrm{u}}$ ultimate soil resistance.

The axial load transfer curves suggested by McVay et al. (1989) are used in this study. Also used are the vertical $\tau$ - $Z$ springs along the side of the pile as described by the equation below:
$Z=\frac{r_{0} \tau_{0}}{G_{i}}\left[\ln \frac{\left(r_{\mathrm{m}}-\beta\right)}{\left(r_{0}-\beta\right)}+\frac{\beta\left(r_{\mathrm{m}}-r_{0}\right)}{\left(r_{\mathrm{m}}-\beta\right) \times\left(r_{0}-\beta\right)}\right]$,

where $\beta=r_{0} \tau_{0} / \tau_{\mathrm{f}} ; r_{0}$ is the radius of the pile; $\tau_{0}$ shear stress transferred to the soil for a given $Z$ displacement; $r_{\mathrm{m}}$ radius out from the pile where shear stress is negligible; $G_{i}$ initial shear modulus; $\tau_{\mathrm{f}}$ ultimate shear stress at the point of interest on the pile.

As for the nonlinear tip spring $(\mathrm{Q}-\mathrm{Z})$, the following relation given by the following equation is used:

$Z=\frac{Q_{\mathrm{b}}(1-v)}{4 r_{0} G_{i}\left(1-\frac{Q_{\mathrm{b}}}{Q_{\mathrm{f}}}\right)}$,

where $Q_{\mathrm{f}}$ ultimate tip resistance, $G_{i}$ initial shear modulus, $v$ Poisson's ratio of the soil, $r_{0}$ radius of the pile, and $Q_{\mathrm{b}}$ mobilized tip resistance for the given displacement $Z$.

The following soil properties are used for sand to represent its resistance in both the lateral and axial directions: angle of internal friction $\phi$ (evaluated from the laboratory experiments), Poisson's ratio $v$ (a typical value of 0.3 is used), ultimate skin friction $\tau_{\mathrm{f}}$ (evaluated from Tomlinson's equation), ultimate tip resistance $Q_{\mathrm{f}}$, and shear modulus $G_{i}$ (Kulhawy and Mayne 1990). For the analysis reported herein, the following properties were employed for the loose sand: angle of internal friction $\phi$ of $30^{\circ}$, shear modulus $G_{i}$ of $9.615 \mathrm{MN} / \mathrm{m}^{2}$, unit weight of soil of $17 \mathrm{kN} /$ $\mathrm{m}^{3}$ and relative density of $35 \%$.

The frame is loaded with a central-concentrated load, UDL and eccentric-concentrated load at a nominal eccentricity of $10 \%$ of length of the beam (with eccentricity measured from the center of the beam) in increments as applied in the experimental program and the response in terms of deformations, rotations, shear forces and bending moments is obtained for each load increment.

\section{Experimental program}

\section{Geotextile}

The wide-width tensile strength test is a popular method to evaluate properties of various geosynthetics. Various studies have been conducted by many researchers about the effects of sample preparation on the test results. However, it is known that there is no universal relationship between specimen sizes and test results (Koerner 1998). In this study, a woven geotextile of $200 \mathrm{~mm}$ width by $500 \mathrm{~mm}$ length was chosen for the specimen to satisfy the ASTM recommendations. The load-deformation property obtained from the wide-width tensile test is plotted in Fig. 2 which resembles the behavior reported by Kim and Frost (2005). 
Fig. 1 Modeling of the frame with plinth beam along with the pile groups

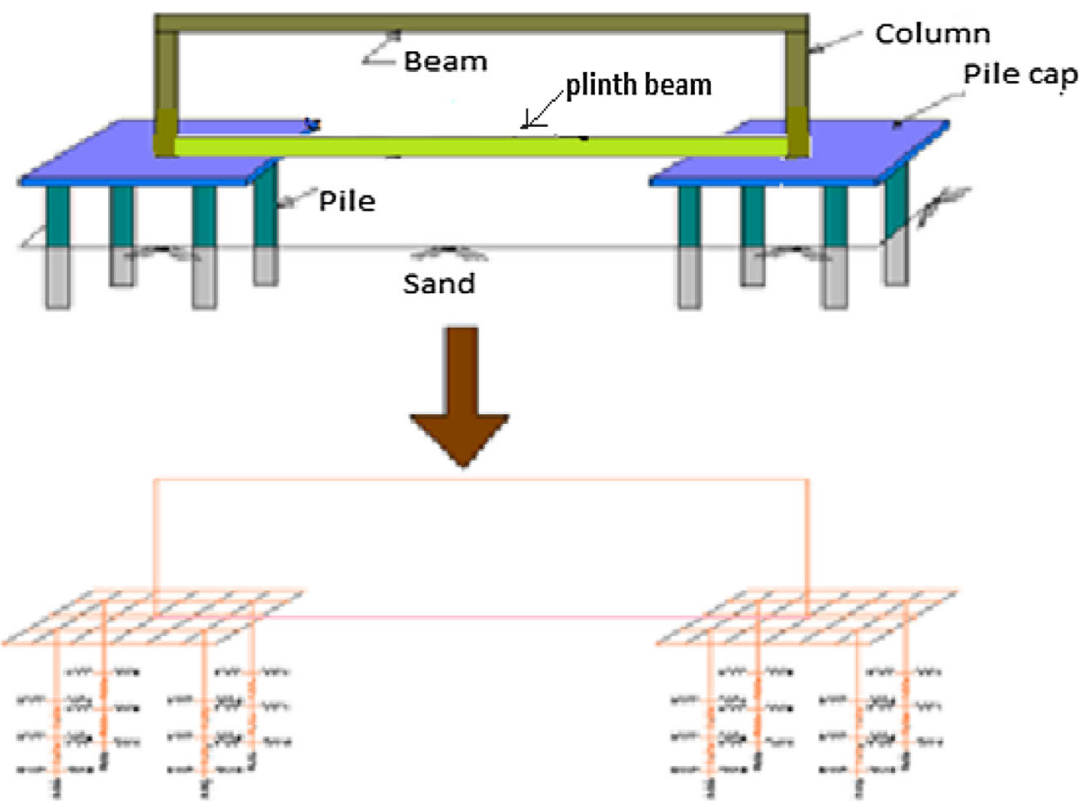

\section{Frame and pile groups}

Using the scaling law proposed by Wood et al. (2002) and reproduced in Eq. (4), the material and dimensions of the model were selected:

$\frac{E_{m} I_{m}}{E_{p} I_{p}}=\frac{1}{n^{5}}$,

where $E_{m}$ is modulus of elasticity of model, $E_{p}$ is modulus of elasticity of prototype, $I_{m}$ is moment of inertia of model, $I_{p}$ is moment of inertia of prototype, and $1 / n$ is scale factor for length.

An aluminium tube with an outer diameter of $16 \mathrm{~mm}$ and inner diameter of $12 \mathrm{~mm}$ was selected as the model pile with a length scaling factor of $1 / 10$. This is used to simulate the prototype pile of a $350-\mathrm{mm}$ diameter solid

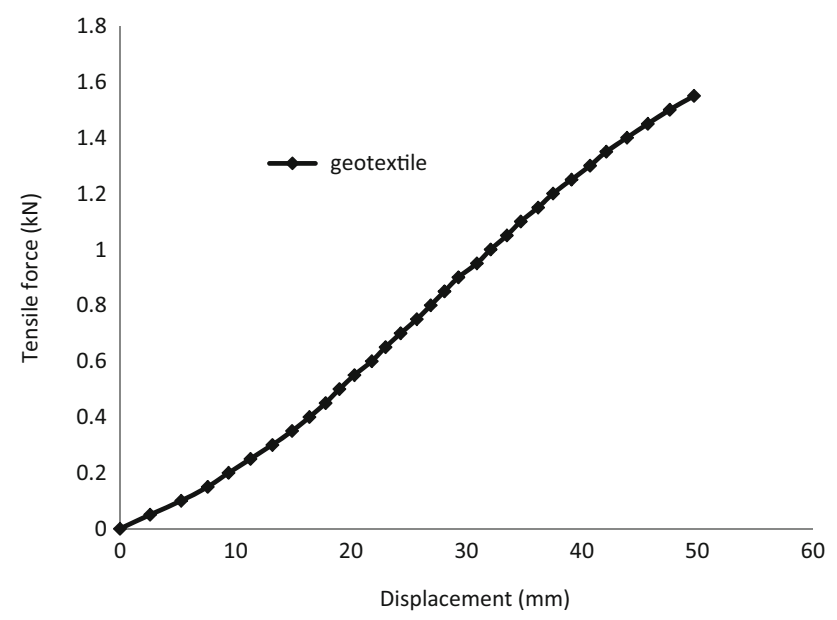

Fig. 2 Load-deformation plot of Woven geotextile section made of reinforced concrete. Columns of height $3.2 \mathrm{~m}$, beam of span $5 \mathrm{~m}$ and plinth beam of the plane frame were scaled in the same manner. Aluminium plates of $13 \mathrm{~mm}$ thickness were used as the pile caps. In the pile group setup, pile spacing of eight diameter (8D) was adopted and the length of the piles was so selected as to maintain a length to diameter $(L / D)$ ratio of 20 (Chandrasekaran and Boominadhan 2010). The sufficient freestanding length was maintained from the bottom of the pile cap to the top of the soil bed. Beam column junctions were made by welding for the fixed condition. Geotextile is wound around the bases of the columns to form a loop and to act as a plinth beam. Screwing of the piles and columns in the threads provided in the pile cap leads to partial fixity condition. The scaling factors used in the study are presented in Table 1.

\section{Experimental setup and instrumentation}

The schematic diagram of the test setup is shown in Fig. 3a Tests were conducted on the model pile groups with the frame embedded in sand bed in a testing chamber, which was well instrumented with the dial gauges of sensitivity $0.002 \mathrm{~mm}$ to study the lateral, vertical displacements and rotations at the base of the column. From the photograph of the test setup shown in Fig. 3b it can be understood that the horizontal displacement is measured with a dial gauge arranged at pile cap instead of the base of the column. The reason being the pile cap is taken as a rigid element. The same is the case with the dial gauge setup for rotation measurement. For the convenience of experimentation the positions of dial gauges shown in Fig. 3a have been setup as shown in Fig. 3b without affecting the test results. Loads 
Table 1 Scaling factors used in the study

\begin{tabular}{lllllll}
\hline Variable & Length & Density & Stiffness & Stress & Strain & Force \\
\hline Scaling factors & $1 / 10$ & 1 & $1 / 10$ & $1 / 10$ & 1 & $1 / 10^{3}$ \\
\hline
\end{tabular}

(a)

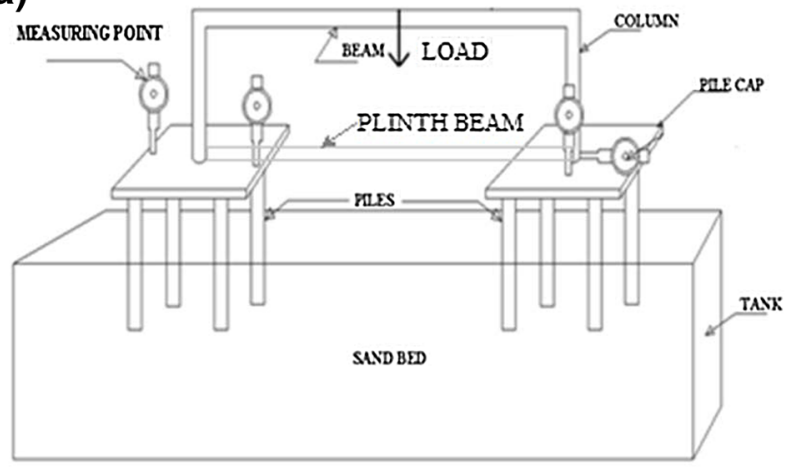

(b)

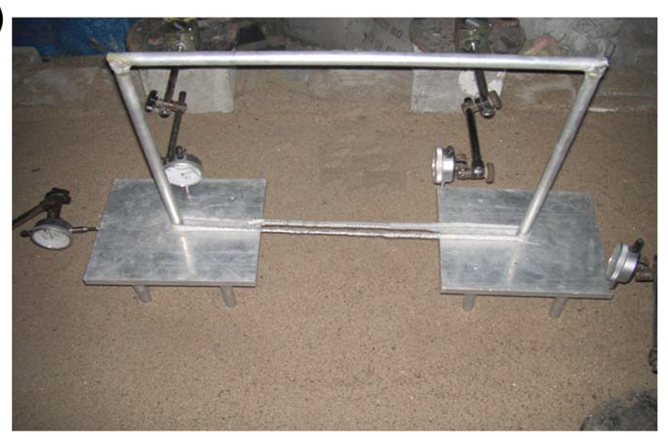

Fig. 3 a Schematic diagram of the test setup. b Photograph of the test setup

on the frame were applied through the hooks provided to the beam at required locations according to the type of loads on the beam. The model frame was placed at the center of the testing chamber using the templates. The sand is then poured into the testing chamber gently through the pores of a steel tray in layers to attain the loose state and uniformity for the sand bed. The installation procedure simulates the bored pile condition.

\section{Test procedure}

Static vertical loads were applied on the model frame with geotextile as plinth beam by placing weights on the hangers. The loads were applied in increments and were maintained for a minimum period to allow the deflections to stabilize, which means that the short-term deflections are considered for the analysis and long-term deflections of soil are neglected. During the application of static loads, the lateral, vertical displacements at the base of the column and the rotation of the pile cap were measured using the instrumentation setup as described earlier.

\section{Testing phases}

Static vertical load tests were conducted on the model frame with geotextile as plinth beam supported on pile groups embedded in the sand bed shown in Fig. 3a. Tests were conducted in the following sequence:

1. Central-concentrated load is applied in increments (1, $2,3 \mathrm{~kg}$, etc.) at the center of the beam.

2. The beam is loaded at third point with equal loads in increments $(3,6,9 \mathrm{~kg}$, etc.) to simulate the uniformly distributed load (UDL) condition.

3. Eccentric-concentrated load is applied in increments $(1,2,3 \mathrm{~kg}$, etc.) at a nominal eccentricity of $10 \%$ of the span of the beam.

\section{Results and discussion}

\section{Lateral displacement, settlement and rotation at the base of the column from the experimental results and nonlinear FEA}

Figure $4 a, b$ represents the variation of the lateral displacement with the static load applied on the frame as central-concentrated load and uniformly distributed load. From the plots shown herein, it is observed that the displacement from the experiment shows a variation of not more than $15 \%$ with respect to that from the nonlinear FEA. Hence, the displacement from the experiment is in good agreement with that by the nonlinear FEA.

Figure $5 \mathrm{a}, \mathrm{b}$ represents the variation of the lateral displacement with the static load applied on the frame as eccentric-concentrated load. From the plots shown herein, it is observed that the behavior of frame with geotextile as plinth beam at far end after certain level of loading, the increase in the lateral displacement is decreased. In case of frame with geotextile as plinth beam the base of the column at near end and far end moves outward when the load applied on the frame is less. As the load on the frame increases the displacement at far end gets reduces because of the rigidity of the plinth beam. The displacement from the experiment shows a variation of not more than $15 \%$ with respect to that from the nonlinear FEA. Hence, the displacement from the experiment is in good agreement with that by the nonlinear FEA.

The variation of settlement at the base of the column with respect to the central-concentrated load and UDL on 
(a)

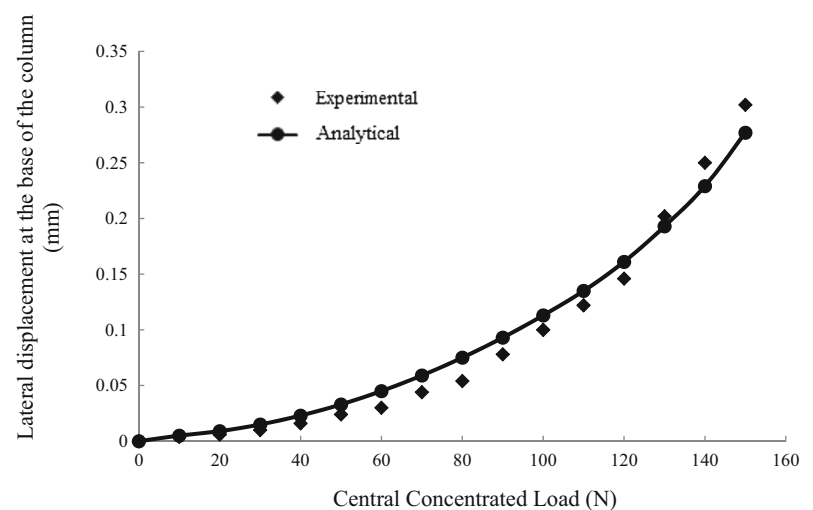

(b)

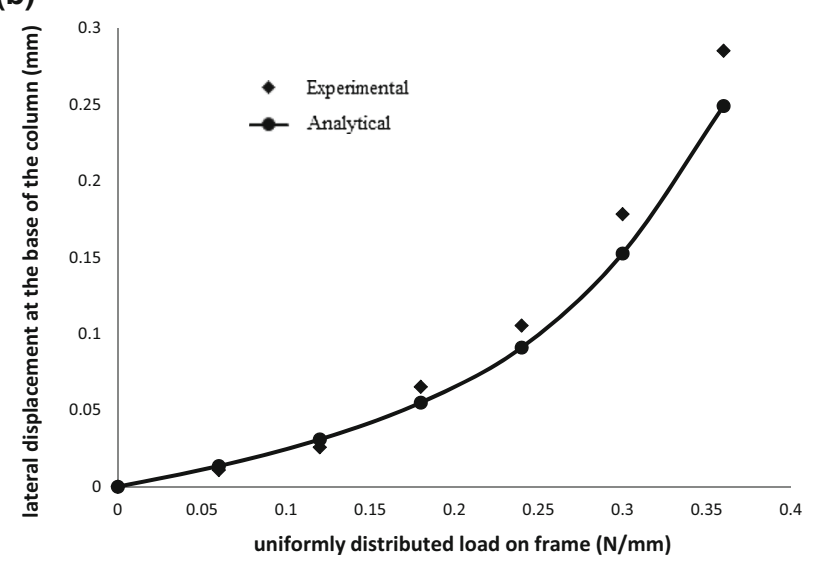

Fig. 4 a Lateral displacement at the base of the column for central point load. b Lateral displacement at the base of the column for UDL

the frame is presented in Fig. 6a and b, respectively, and the variation of settlement at the near end and far end of the column base for the frame under the eccentric-concentrated load is presented in Fig. 7a and b, respectively. From the plots mentioned herein, it is observed that the settlement from the experiment shows a variation of not more than $15 \%$ with respect to that from the nonlinear FEA for central-concentrated load and uniformly distributed load on the frame. For eccentrically loaded frame at near end, the variation is not more than $13 \%$, at far end it is not more than $14 \%$. Hence, the displacement from the experiment is in good agreement with that by the nonlinear FEA.

The variation of rotation at the base of the column for the central-concentrated load and UDL applied on the frame is presented in Fig. 8a and b, respectively. Meanwhile, the variation of rotation at the column base of the near and far end of the frame under the eccentric-concentrated load is presented in Fig. 9a and b, respectively. From the plots it is observed that, for eccentric-concentrated load on the frame, rotation at far end after certain level of loading the increase in rotation is decreased. This is (a)
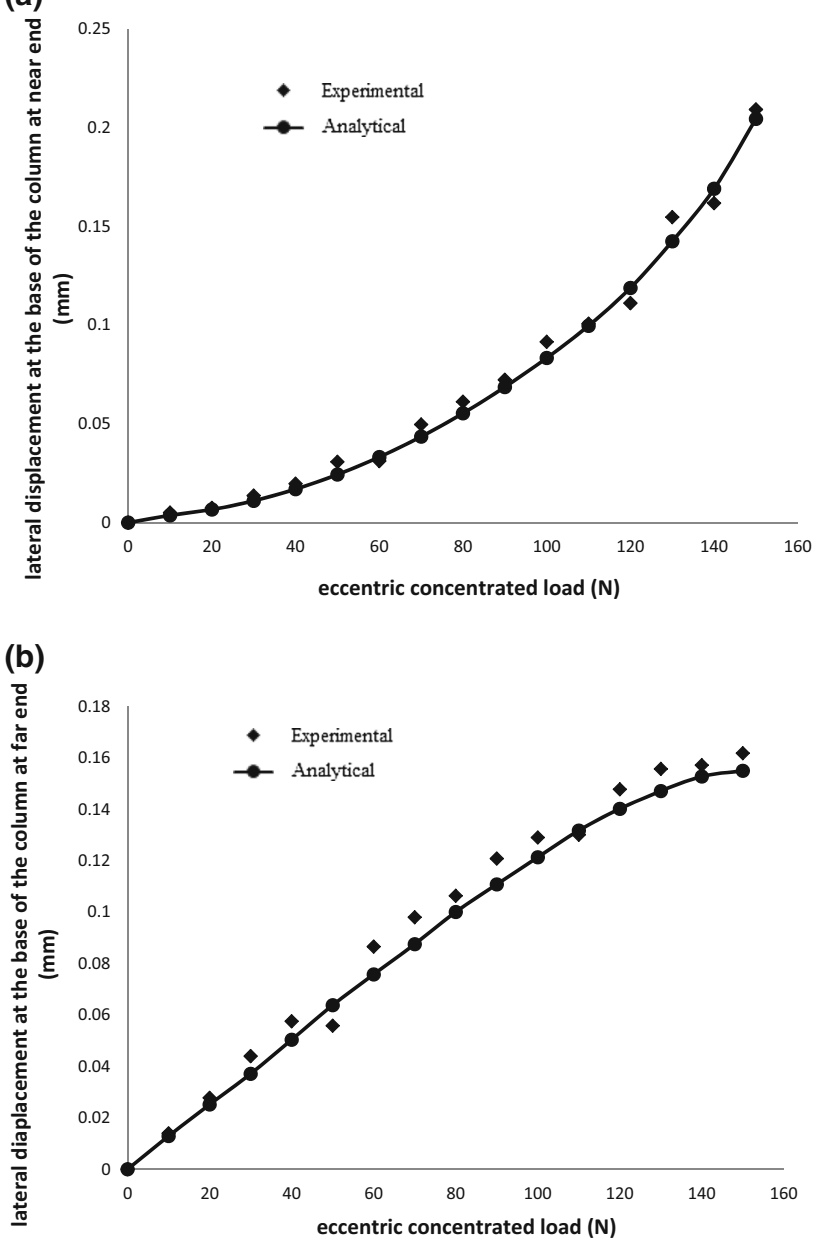

Fig. 5 a Lateral displacement at the base of the column at near end for eccentric point load. b Lateral displacement at the base of the column at far end for eccentric point load

expected because of the tensile strength of the geotextile comes into picture at higher level of loading. The rotations from the experiment show a variation of $7-14 \%$ with respect to that from the nonlinear FEA. Hence, the displacement from the experiment is in good agreement with that by the nonlinear FEA.

\section{Shear force in the frame by conventional method, experiments and nonlinear FEA}

The shear force in the frame under the central-concentrated load, UDL, and eccentric-concentrated load has been plotted in Fig. 10a-c, respectively. From these plots, it can be observed that the shear force predicted by the conventional method is always on the higher side. The shear force predicted by the conventional method is $40-50 \%$ more than that of the frame with geotextile as plinth beam when loaded with central-concentrated load, uniformly distributed load and eccentric point load. The shear force 

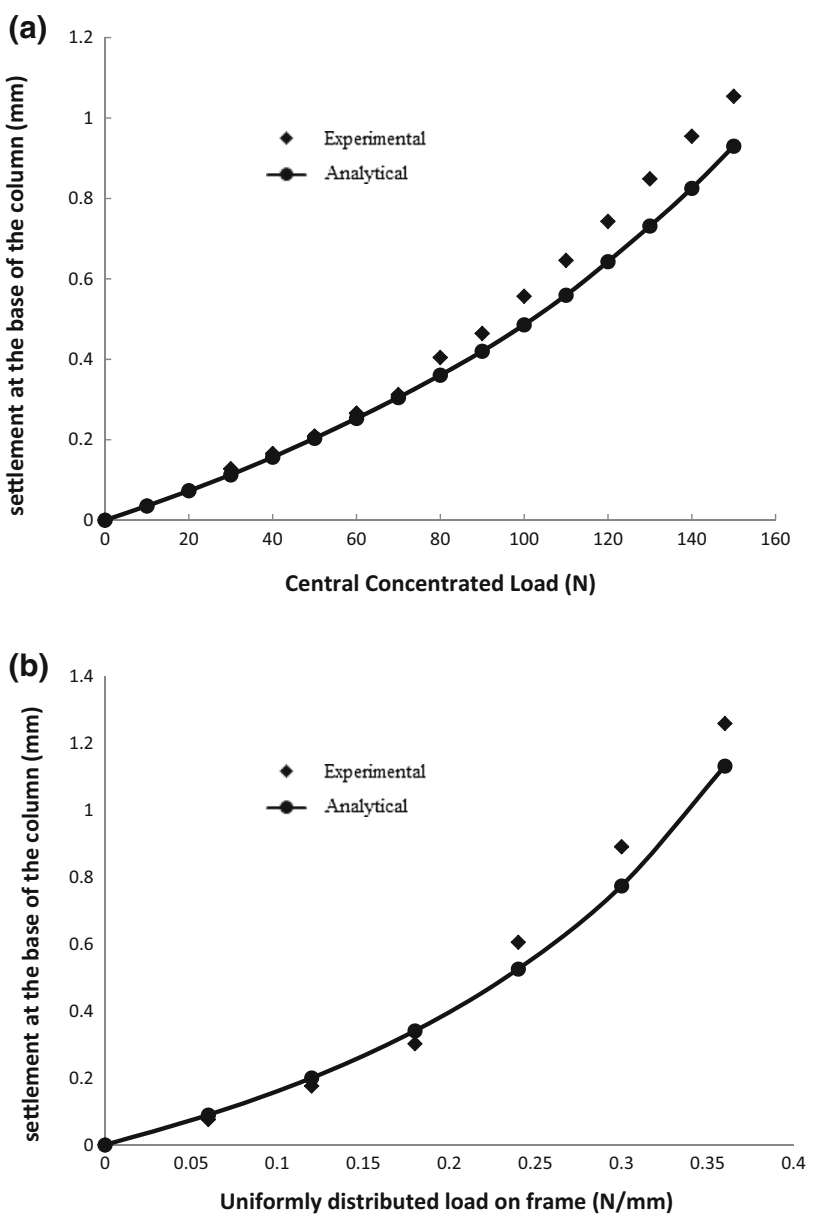

Fig. 6 a Settlement at the base of the column for central point load. b Settlement at the base of the column for UDL

obtained from the experiment deviates by $8-10 \%$ of that given by the nonlinear FEA, which indicates that the nonlinear soil model is in good agreement with the experimental results.

\section{Bending moment at top of the column by conventional method, experiments and nonlinear} FEA

The bending moment at the top of the column of the frame under the central-concentrated load and UDL is plotted in Fig. 11a and b, respectively, and the one of the near end and far end, respectively, of the frame under the eccentric load is plotted in Fig. 12a, b. From the above figures, it is observed that the bending moment predicted by the conventional method is higher than that by the other methods of analysis, indicating that the conventional method of analysis for obtaining the design (a)

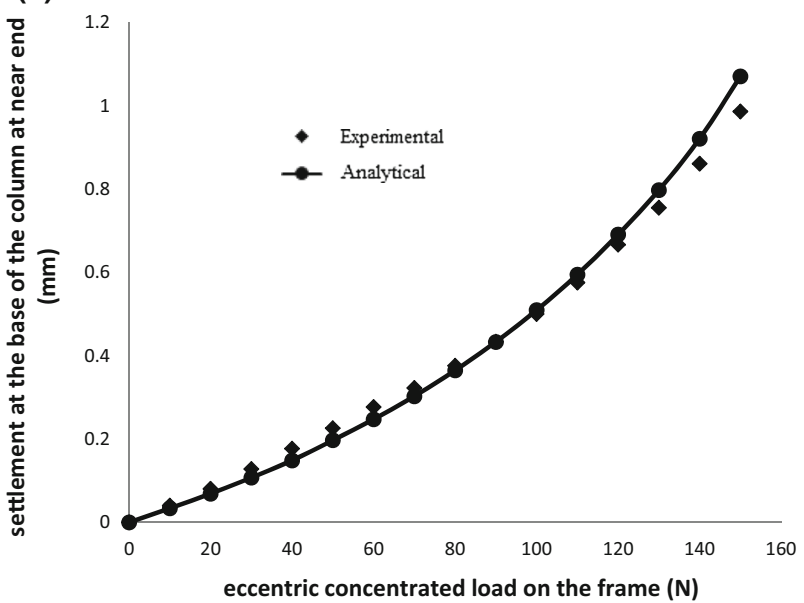

(b)

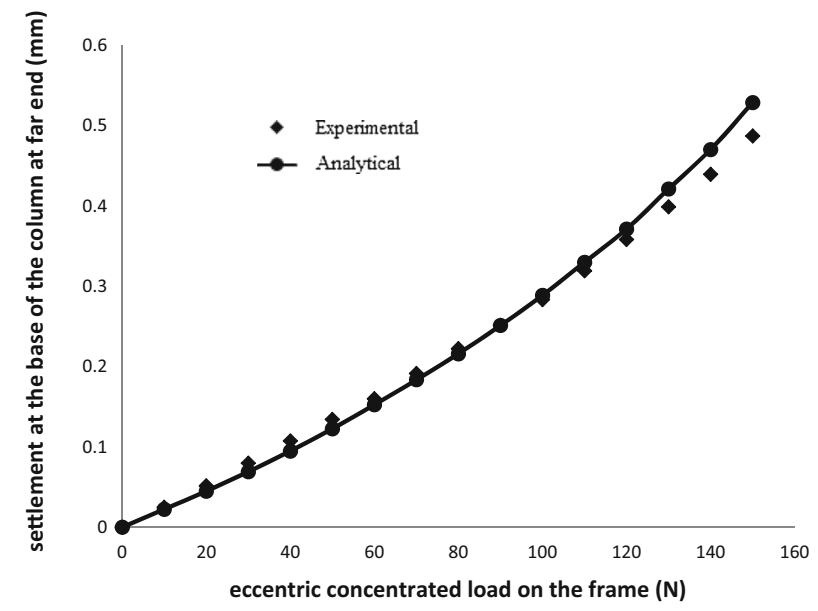

Fig. 7 a Settlement at the base of the column at near end for eccentric point load. b Settlement at the base of the column at far end for eccentric point load

moment is uneconomical. When the geotextile is used as plinth beam the bending moment at top is reduced by $10-17 \%$ compared with the conventional method. This indicates the need for consideration of soil interaction and use of geotextile as plinth beam in evaluating the design parameters in a building frame. The values of bending moment predicted by the nonlinear FEA and experiments differ by $2-5 \%$ only, which indicates that the nonlinear soil model is well suited for representing the nonlinear behavior of soil. The point to be noted with respect to the bending moments at the top of the column of the frame predicted by different methods is that though the percentages of variation may not be great, the differences are significant because the magnitudes of bending moment are of multiples of thousands. 
(a)

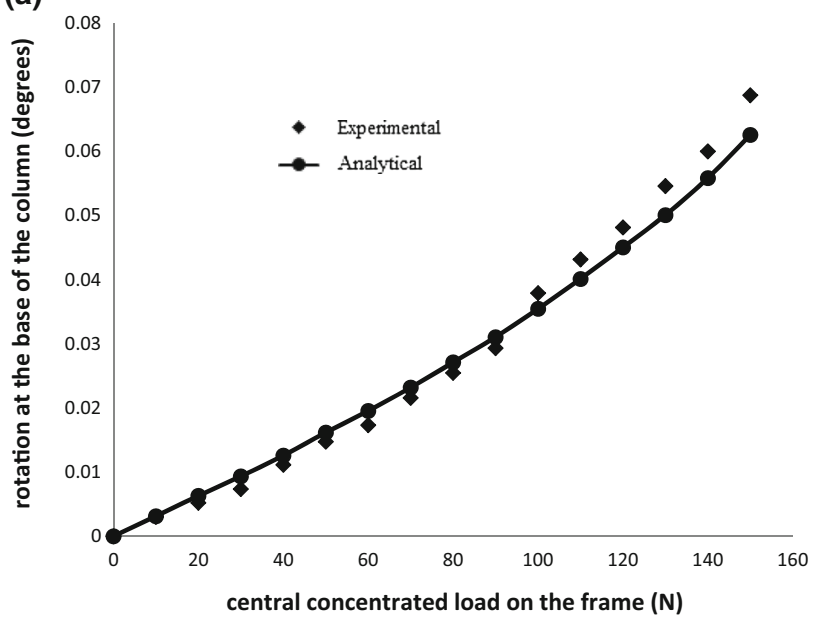

(b)

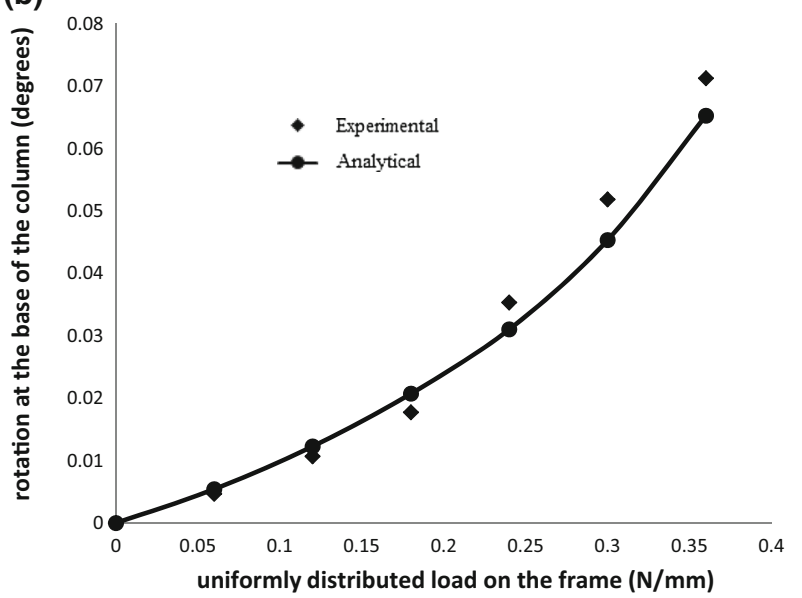

Fig. 8 a Rotation at the base of the column for central point load. b Rotation at the base of the column for UDL

\section{Bending moment at the base of the column by the conventional method, experiments and nonlinear FEA}

The variation of bending moment at the base of the column of the frame under the central-concentrated load and UDL has been plotted in Fig. 13a and b, respectively. Figure 14a and $b$ shows the variation of bending moment at the base of the column of the near end and far end, respectively, of the frame under the eccentric-concentrated load. These figures show that the conventional method gives a bending moment $90 \%$ higher value than that of the bending moment of frame with geotextile as plinth beam. Hence, from the above, it is to be noted that the soil interaction of frame with geotextile as plinth beam is greatly reducing the (a)

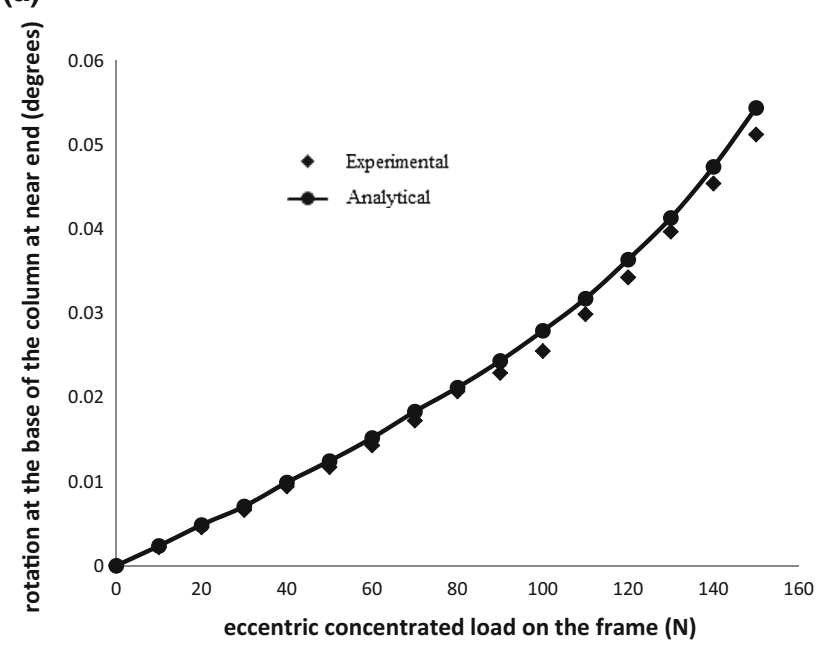

(b)

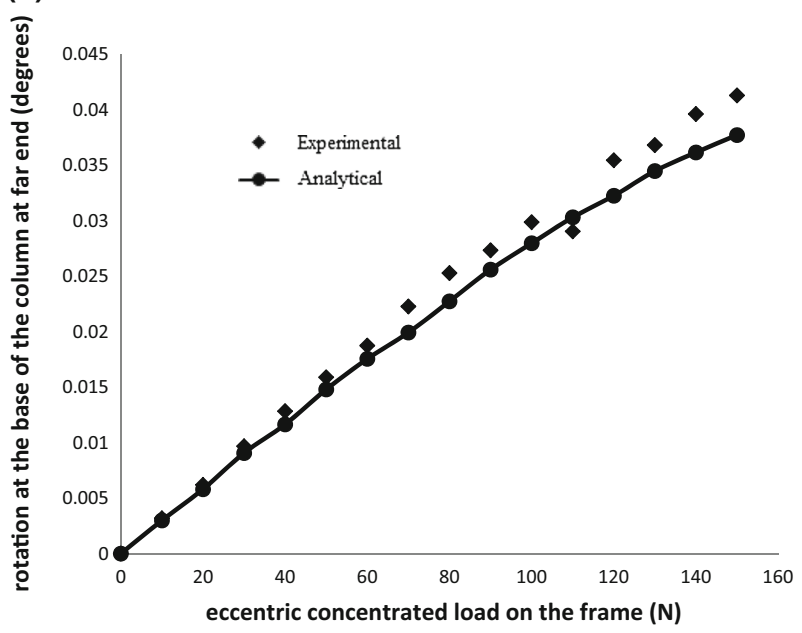

Fig. 9 a Rotation at the base of the column at near end for eccentric point load. b Rotation at the base of the column at far end for eccentric point load

bending moment which will emphasize the need to use the geotextile as plinth beam.

The bending moments given by the experiments agree well with those by the nonlinear FEA with a variation of $5-15 \%$. Moreover, the bending moment at the base of the column changes its sign, when the load reaches some value. The sign change of the bending moment is observed to occur at an earlier stage of loading at near end than at the far end for eccentric-concentrated load. This is due to the fact that for relatively smaller loads on the frame, the column is rigidly connected to the pile cap and the soil is in 

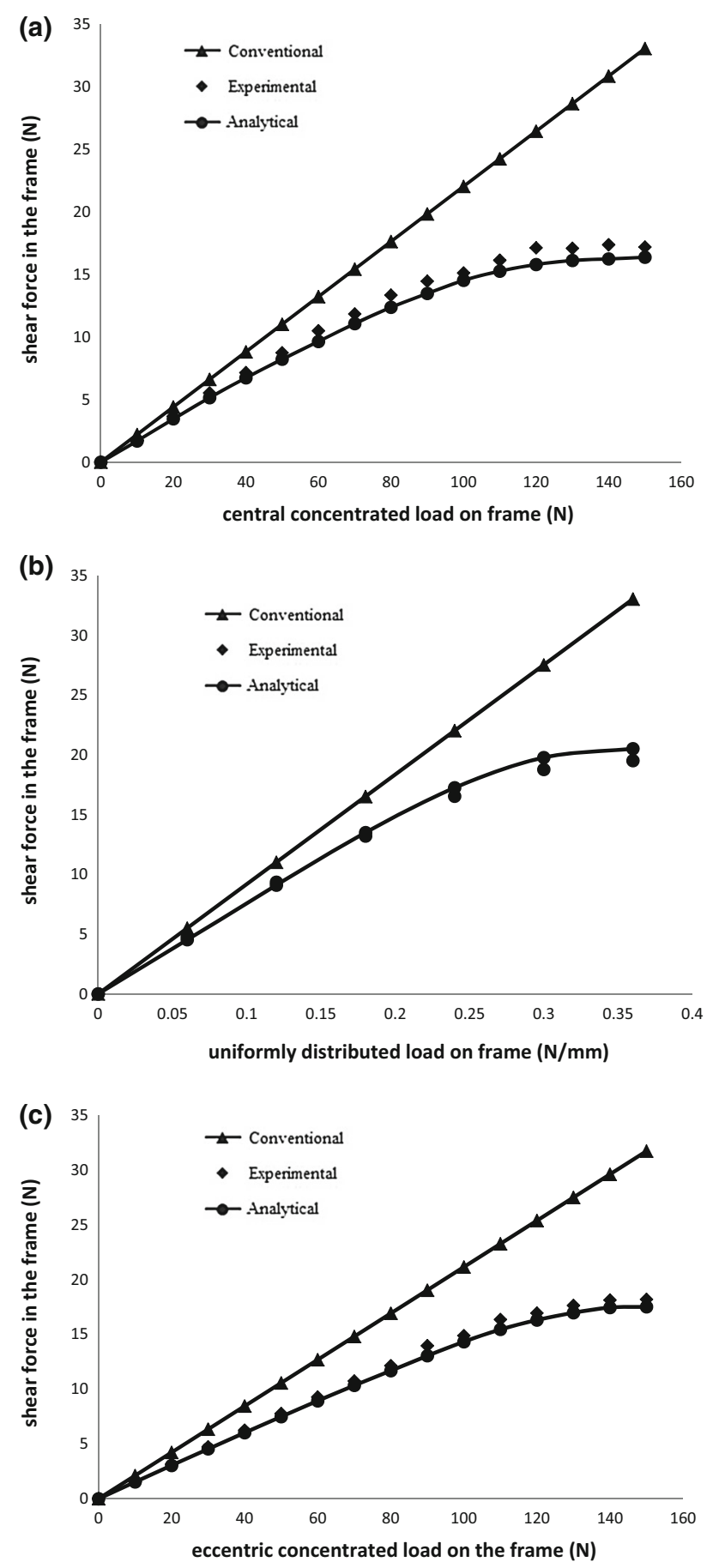

Fig. 10 a Shear force in the frame for central point load. b Shear force in the frame for UDL. c Shear force in the frame for eccentric point load

its linear range, hence it behaves like a frame with fixed base. As the load on frame increases, the connection between base of the column and pile cap becomes partially rigid, the behavior of the soil will be in the nonlinear range and increase in the rotation of the pile cap will be so high, (a)

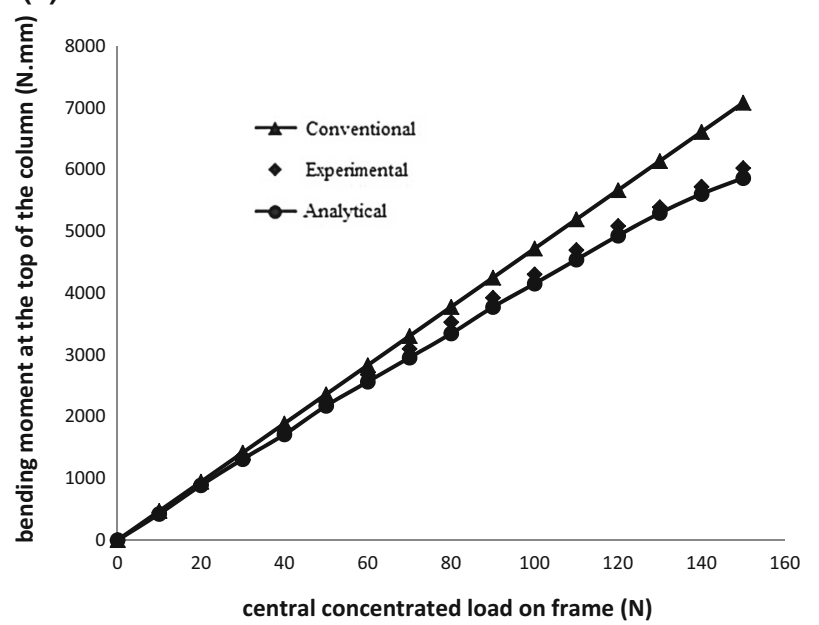

(b)

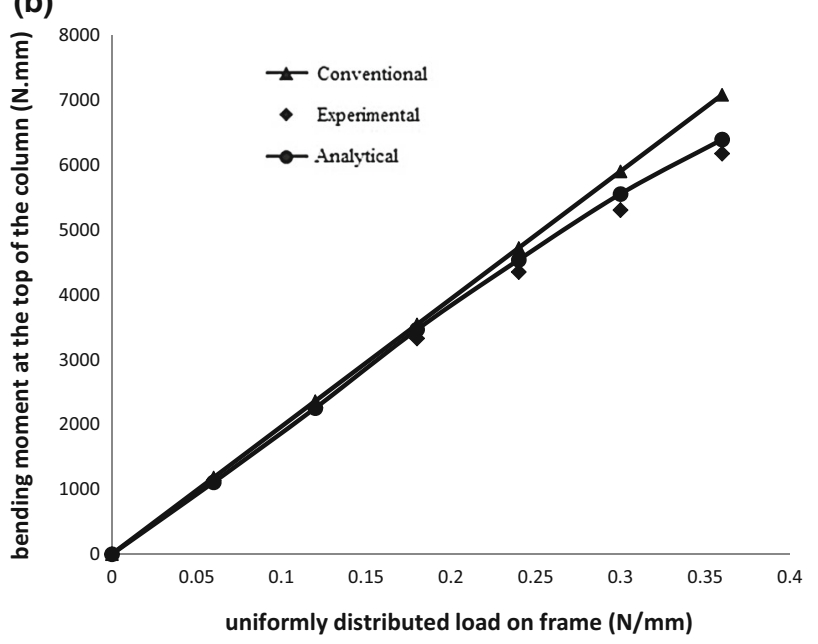

Fig. 11 a Bending moment at the top of the column for central point load. b Bending moment at the top of the column for UDL

hence the nature of bending of column at the base will change its sign.

\section{Conclusions}

Based on the results of the present experimental and numerical investigations on the model building frame resting on pile groups embedded in cohesionless soil, the following conclusions are drawn:

- As the load on the frame increases, the behavior of the frame in terms of displacement and rotation at the base of the column predicted by nonlinear FEA and experiment appears to be linear for relatively smaller loads and for higher load range they show a nonlinear variation. 
(a)

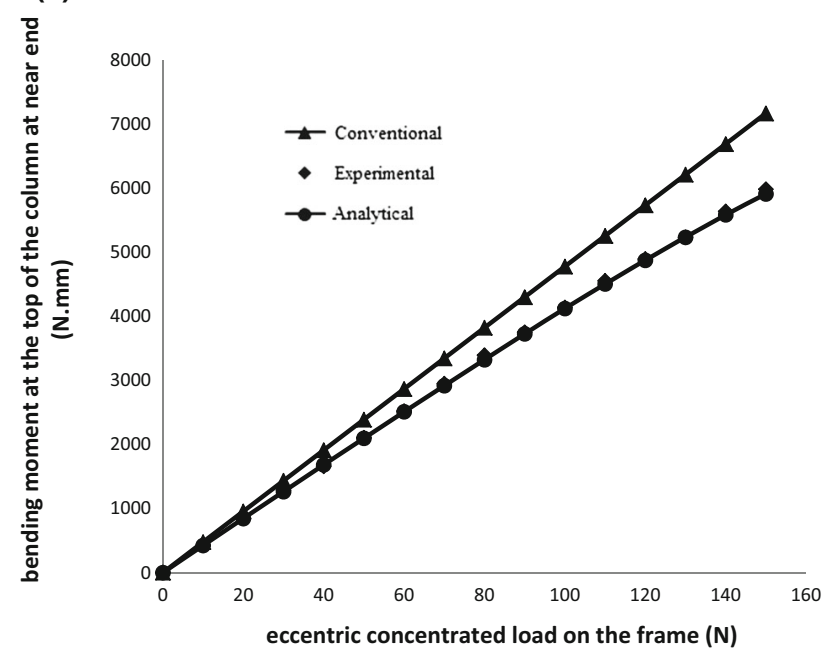

(b)

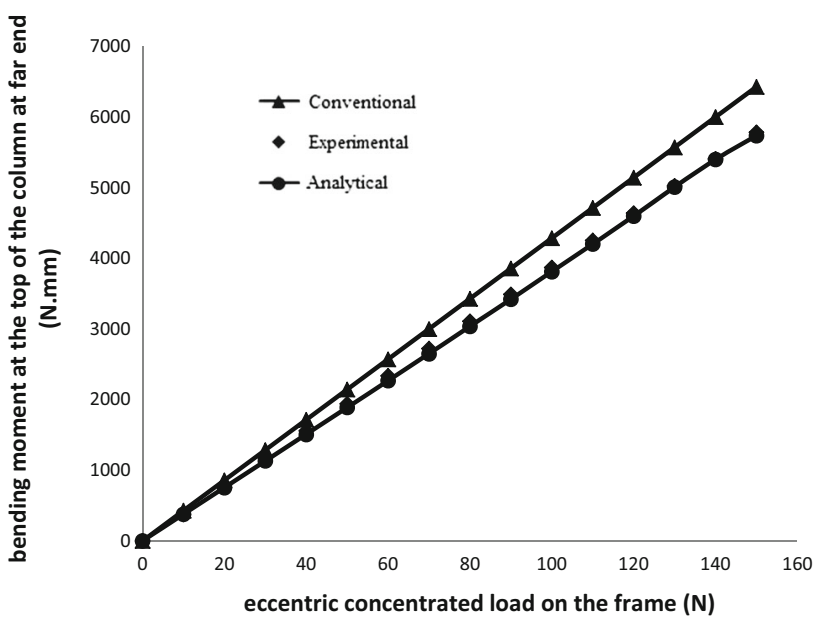

Fig. 12 a Bending moment at the top of the column at near end for eccentric point load. $\mathbf{b}$ Bending moment at the top of the column at far end for eccentric point load

- When the geotextile is used as plinth beam considerable reduction in lateral displacements and rotations is observed but not much effect is seen in settlements. In case of eccentric-concentrated load at far end the increase in lateral displacements and rotations is decreased after certain level of loading.

- The displacements and rotations from the experimental results and the nonlinear FEA show a maximum difference of not more than $15 \%$, indicating that the nonlinear curves used to characterize the soil behavior are generally good for representing the load-displacement response of the soil.

- The conventional method of analysis gives a shear force of about $40-50 \%$ higher than that by the nonlinear FEA for the frame with geotextile as plinth beam. As the load acting on the frame increases, the percentage (a)

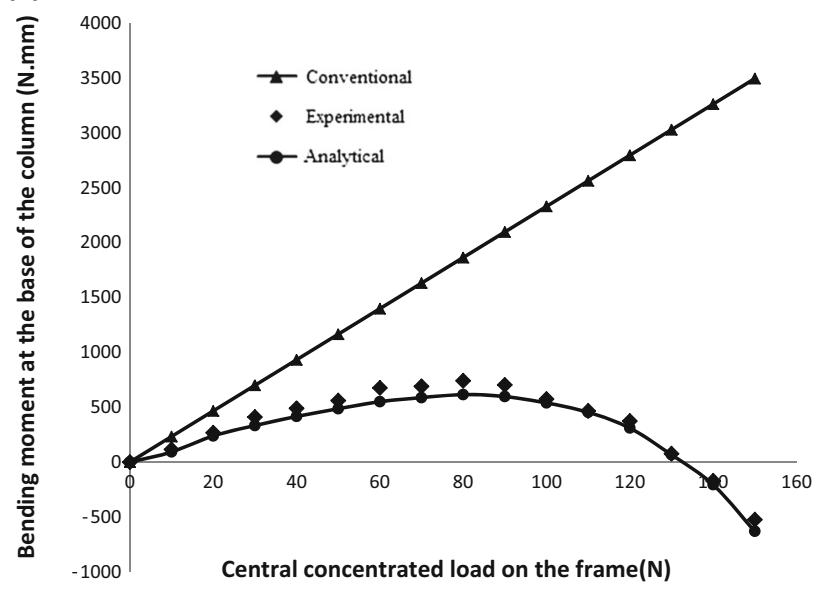

(b)

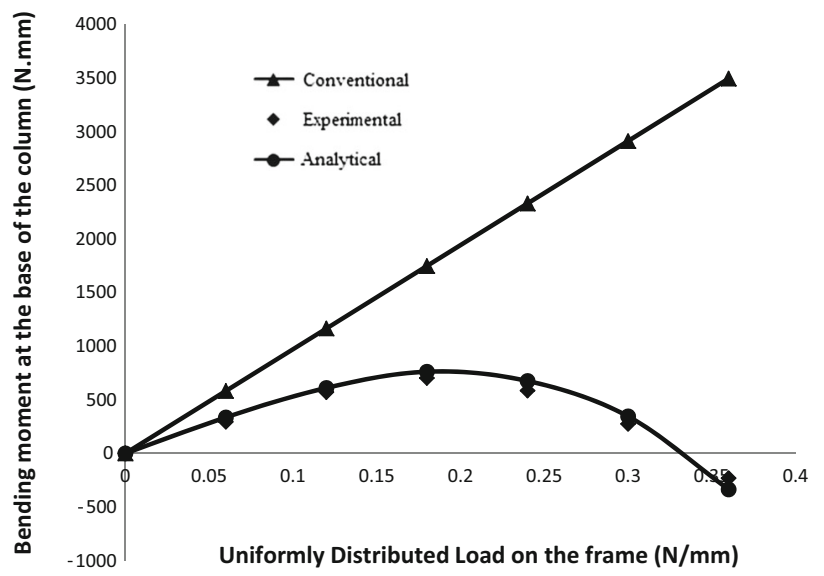

Fig. 13 a Bending moment at the base of the column for centralconcentrated load. b Bending moment at the base of the column for UDL

of variation of shear force predicted by the conventional method with respect to that of the experimental result also increases.

- The conventional method gives a bending moment at the top of the column that is about $10-17 \%$ higher than that by the nonlinear FEA for the frame with geotextile as plinth beam but such a difference is still significant as the bending moment values are in multiples of thousands. The bending moment at the near end of the frame is higher than that of the far end for the eccentricconcentrated load case.

- The conventional method gives a bending moment at the base of the column that is about $85 \%$ higher than that by the nonlinear FEA for the frame with geotextile as plinth beam. For a nominal eccentricity given for the concentrated load (10\% length of the beam), the conventional method and nonlinear FEA for the frame with geotextile as plinth beam gives a higher value of 
(a)

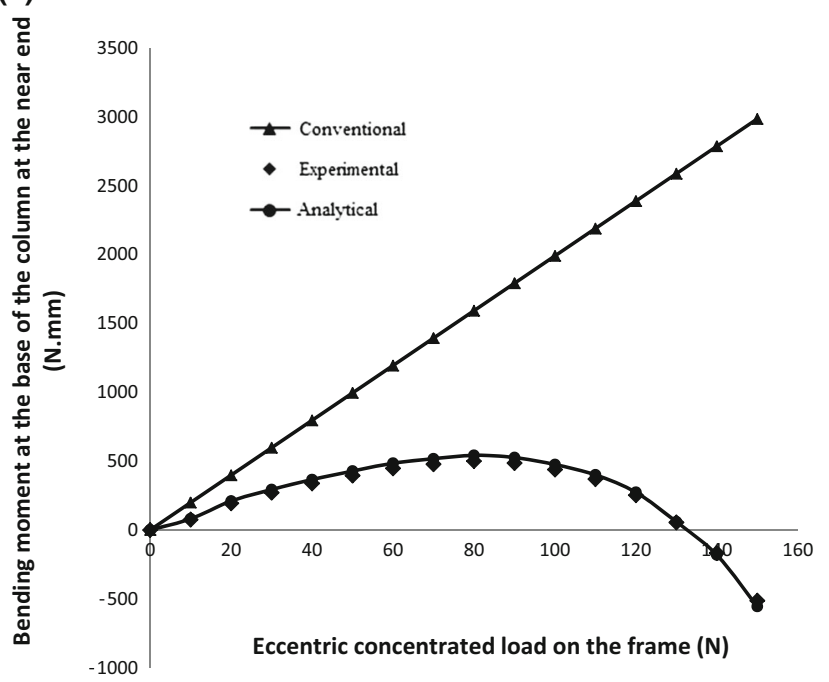

(b)

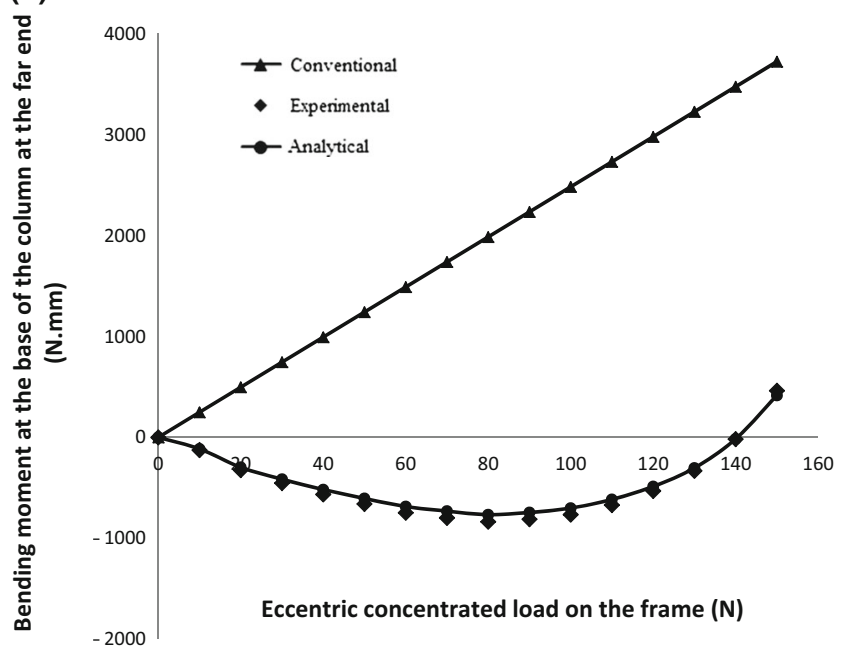

Fig. 14 a Bending moment at the base of the column at near end for eccentric point load. b Bending moment at the base of the column at far end for eccentric point load

bending moment at the column base of the far end from the load than the one of the near end. The reason behind this behavior is the displacements and rotations at far end were reduced when geotextile is used as plinth beam.

The response of the frame in terms of the design parameters (i.e., shear and bending moment) from the conventional method of analysis is always on the higher side irrespective of the level of loading, which reveals the need for consideration of the interaction between the building frame with geotextile as plinth beam, pile foundation, and soil.
Open Access This article is distributed under the terms of the Creative Commons Attribution 4.0 International License (http://crea tivecommons.org/licenses/by/4.0/), which permits unrestricted use, distribution, and reproduction in any medium, provided you give appropriate credit to the original author(s) and the source, provide a link to the Creative Commons license, and indicate if changes were made.

\section{References}

American petroleum Institute (1987) Recommended practice for planning, designing, and constructing fixed offshore platforms, 2A, 17th edn. API Recommended Practice

Basack S (2008) A boundary element analysis of soil-pile interaction under lateral cyclic loading in soft cohesive soil. Asian J Civ Eng (Building and Housing) 4(9):377-388

Basack S, Purkayastha RD (2007) Behaviour of single pile under lateral cyclic load in marine clay. Asian J Civ Eng (Building and Housing) 4(8):443-458

Buragohain DN, Raghavan N, Chandrasekaran VS (1977) Interaction of frames with pile foundation. In: Proceedings of International Symposium on Soil-Structure Interaction, Roorkee, India

Chamecki C (1956) Structural rigidity in calculating settlements. J Soil Mech Found Div ASCE 82(1):1-19

Chandrasekaran SS, Boominadhan A (2010) Group interaction effects on laterally loaded piles in clay. J Geotech Geoenviron Eng ASCE 136:573-582

Chore HS, Ingle RK (2008) Interaction analysis of building frame supported on pile group. Indian Geotech J 38(4):483-501

Dasgupta S, Dutta SC, Bhattacharya G (1998) Effect of soil-structure interaction on building frames on isolated footings. J Struct Eng SERC 26(2):129-134

Deshmukh AM, Karmarkar SR (1991) Interaction of plane frames with soil. In: Proceedings of Indian Geotechnical Conference Surat India

Ingle RK, Chore HS (2007) Soil-structure interaction analysis of building frames-an overview. J Struct Eng SERC 34(5):201-209

Kim D, Frost JD (2005) Multi-scale assessment of geotextilegeomembrane interaction. In: NAGS 2005/GRI 19 Conference Las Vegas 8-9

Koerner RM (1998) Designing with geosynthetics. Prince Hall Fourth, Upper Saddle River, pp 761-762

Kulhawy FH, Mayne PW (1990) Manual on estimating soil properties for foundation design. EPRI Rep 5(1):5-25

Lee IK, Brown PT (1972) Structures and foundation interaction analysis. J Struct Div ASCE 11:2413-2431

Lee IK, Harrison HB (1970) Structures and foundation interaction theory. J Struct Div ASCE 96(2):177-198

Mandal A, Moitra D, Dutta SC (1999) Soil-structure interaction on building frame: a small scale model study. Int J Struct Roorkee 18(2):92-107

McVay MC, Townsend FC, Bloomquist DG, O'Brien M, Caliendo JA (1989) Numerical analysis of vertically loaded pile groups. Proc Found Eng Curr Princ Pract ASCE New York 1:675-690

Meyerhof G (1947) The settlement analysis of building frames. Struct Eng 25:369-409

Meyerhof G (1953) Some recent foundation research and its application to design. Struct Eng 31(6):151-167

Morris D (1966) Interaction of continuous frames and soil media. J Struct Div ASCE 5:13-43 
Noorzaei J, Viladkar MN, Godbole PN (1995) Elasto-plastic analysis for soil-structure interaction in framed structures. Comput Struct 55(5):797-807

Rao PS, Rambabu KV, Allam MM (1995) Representation of soil support in analysis of open plane frames. Comput Struct 56:917-925

Ravi KR, Gunneswara R (2011) Experimental study of a modeled building frame supported by pile groups embedded in cohesionless soil. Interact Multiscale Mech 4(4):321-336
Wood DM, Crew A, Taylor C (2002) Shaking table testing of geotechnical models. Int J Phys Model Geotech 1:1-13

\section{Publisher's Note}

Springer Nature remains neutral with regard to jurisdictional claims in published maps and institutional affiliations. 